\title{
Interactive comment on "Linear and Non-linear Stability Analysis of the Rate and State Friction Model with Three State Variables" by N. Sinha and A. K. Singh
}

\author{
N. Sinha and A. K. Singh \\ aksinghb@gmail.com
}

Received and published: 6 March 2016

We have provided the rebuttal to the reviewer's in the supplement.

Please also note the supplement to this comment:

http://www.nonlin-processes-geophys-discuss.net/npg-2016-11/npg-2016-11-AC1-

supplement.pdf

Interactive comment on Nonlin. Processes Geophys. Discuss., doi:10.5194/npg-2016-11, 2016. 


\title{
NPGD
}

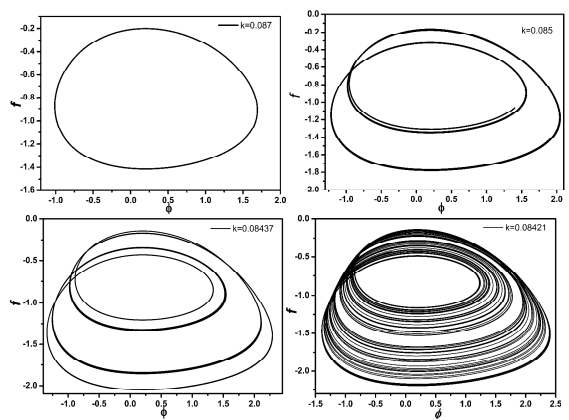

Fig.3-6: Phase diagram $f$ vs. $\phi$ for $k=0.087, k=0.085, k=0.08437$ and $k=0.08421$ $\beta_{1}=1.0, \beta_{2}=0.84, \beta_{3}=0.38, \rho=0.048$ and $\rho_{1}=0.034$ for initial condition $[0,0,0,0]$.

\author{
Interactive \\ comment
}

Fig. 1.

Discussion paper 